\title{
Knowledge and perceptions of prescribers regarding hepatitis B \& C management: a cross-sectional study from Pakistan
}

\begin{abstract}
Objective: The main objective of the study was to assess the knowledge and perceptions of prescribers regarding management of hepatitis B \& $\mathrm{C}$ in the 2 major cities of Pakistan: Islamabad (the national capital) and Rawalpindi (its twin city).

Methodology: A structured questionnaire designed with the help of national standard treatment guidelines for hepatitis B \& C was distributed to a random sample of 400 prescribers. The data were collected, computed and analyzed using SPSS, version 16 program and descriptive analysis was conducted. Kruskal-Wallis and Mann-Whitney tests $(p \leq 0.05)$ were used to compare the knowledge scores of prescribers about standard treatment by profession, length of experience, type of health-care facility, gender, sector and city.
\end{abstract}

Results: The median score for overall knowledge of prescribers regarding treatment 16 was (range 12-24). Eighty percent of the prescribers $(n=320)$ had the opinion that lack of availability and implementation of STGs in hospitals is an important factor which affects overall cost of hepatitis B and C treatment. Forty one percent $(n=167)$ of the prescribers identified oral Lamivudine $100 \mathrm{mg}$ /day as a most effective drug in treatment of hepatitis $B$ and $C$ whereas seventy five percent $(n=300)$ of the respondents agreed that $400 \mathrm{mg}$ ribazole PO BID is a safe dose for anti HBV and HCV treatment.

Conclusion: The results of the present study concluded that the knowledge of prescribers working in public and private healthcare facilities regarding standard treatment regimen of hepatitis B \& C was not adequate but they had positive perceptions towards adherence to the standard treatment guidelines linked to their availability in their healthcare facilities to promote effective management of hepatitis $\mathrm{B} \& \mathrm{C}$.

Keywords: Hepatitis B \& C; Knowledge; Perceptions; Standard treatment guidelines
Volume 5 Issue 5 - 2017

\author{
Madeeha Malik, Azhar Hussain, Erum Abbasi \\ Hamdard Institute of Pharmaceutical Sciences, Hamdard \\ University, Pakistan
}

Correspondence: Madeeha Malik, Hamdard Institute of Pharmaceutical Sciences, Hamdard University, Islamabad, Pakistan,Email madeehamalikI5@gmail.com

Received: June 12, 2017 | Published: October 03, 2017

\section{Introduction}

Hepatitis B virus(HBV) infection is a serious global health problem which affects nearly 2 billion people worldwide and approximately 350 million are suffering from chronic HBV infection. HBV is the 10th leading cause of death worldwide. HBV infections result in 500000 to 1.2 million deaths per year caused by chronic hepatitis, cirrhosis, and hepatocellular carcinoma. ${ }^{1}$ On the other hand, Hepatitis $\mathrm{C}$ virus $(\mathrm{HCV})$ is one of the foremost causes of liver disease worldwide and is also considered as expected major cause of morbidity and mortality in the future. The complex and uncertain geographical distribution of $\mathrm{HCV}$ infection and chronic hepatitis $\mathrm{C}$, determination of associated risk factors and evaluation of cofactors that accelerate its progression underscore the difficulties in prevention and control of $\mathrm{HCV}^{2}$ Unavailability and compromised quality of diagnostic tests for screening of hepatitis B and C infection even in high-risk populations leads to inaccurate data collection and reporting. Similarly, the standardization and methodology of polymerase chain reaction(PCR) testing makes the option of "whom to treat" even more difficult. ${ }^{3}$ Lack of adherence to standard treatment guidelines and costly treatment also contribute as barriers towards hepatitis treatment. The treatment of hepatitis B takes four months to one year depending on patient's physiological response. The routine serological examination and cost of anti-HBV medication is a burden over a patient of poor economic status. Lack of a health-insurance system in developing countries makes it difficult for hepatitis patient to show compliance to the treatment course and follow up. ${ }^{3}$ There is high prevalence and poor control of hepatitis B \& C in Pakistan. Pakistan is highly endemic with $\mathrm{HBV}$ with nine million people infected with HBV and its infection rate is increasing at an alarming rate. Lack of appropriate healthcare facilities, poor economical status, less public awareness about the transmission of major communicable diseases including HBV, HCV and HIV are the main associated factors to its rapid prevalence. The total cost of HCV treatment in Pakistan, including diagnostic tests, physicians' fees, etc., is up to $\$ 1500$, representing more than half of the country's annual per capita income, which is approximately \$2800. Standard treatment guidelines are not thoroughly updated, implemented and practiced for management of hepatitis B and C infection in developing countries including Pakistan. Negligence on the part of policy makers set a smooth path for prescribers who in turn promote brand prescribing without considering disease management protocols and individual patient needs due to which ultimately the desired therapeutic goals are not significantly achieved which has led to poor control of disease. Standard treatment guidelines for hepatitis $\mathrm{B} \& \mathrm{C}$ are not available at healthcare facilities. Most of the studies conducted in Pakistan are on prevalence and therapeutic efficacy of drugs used for hepatitis B \& C, however, there is scanty of evidence based data on KAP and adherence of prescribers to hepatitis B \& C 
guidelines in Pakistan. Thus, the current study has been designed to assess the knowledge, perceptions and adherence of prescribers with guidelines for the treatment of hepatitis B \& C in Pakistan.

\section{Methodology}

\section{Study design}

A descriptive cross-sectional study design was used to evaluate the knowledge and perception of prescribers regarding standard treatment guidelines for the management of hepatitis B \& $\mathrm{C}$ in different sectors of health care system. National bioethical committee is present for this type of research and it states that only institutional head approval is required for this type of study. Beside this approval was obtained for the study from the Ethical Committee of Hamdard University. Moreover in Pakistan, questionnaire-based studies do not need any endorsement from Ministry of Health. Despite that, prior information was sent to the Ministry of Health, Government of Pakistan for the execution of this research. For data collection approval from MS of the hospitals and respective prescribers was taken. Informed and verbal consent for participation was also taken from the respondents. Respondents were ensured for the confidentiality of information verbally as well as confidentiality under taking was signed by the principal investigator.

\section{Sampling of facilities and respondents}

This study was conducted from June to August 2015. All the registered prescribers in the vicinity of Rawalpindi and Islamabad were respondents of the study including those who manage patients at public or private hospitals or those who run their private clinics. Prescribers managing patients as house officers, medical officers, consultants/specialists as well as general practitioners were included in the study as respondents. Calculations of sample size were performed using Raosoft ${ }^{\circledR}$ sample size calculator to determine the size of sample that represents the population of prescribers (Raosoft, 2004). Considering population of prescribers $(\mathrm{N}=62920)$, the sample size was calculated to be four hundred to achieve ninety five percent confidence level with five percent margin of error. Prescribers were selected randomly from the two cities. The prescribers were contacted and given an explanation of the purpose of the study and their verbal consent to participate in the study was obtained.

\section{Study tool}

A structured questionnaire was developed through focus group discussions by using the national standard treatment guideline for treatment of pulmonary tuberculosis as a reference. Two focus group discussions were carried out at different time intervals with 4 different groups of experts including clinicians, specialists, physicians and doctors from academia. Each group comprised 3-4 participants for the development, finalization, face and content validity of the data collection tool. Pilot testing was carried out on 40 prescribers(10\%) of the total sample size before beginning the final study. A Cronbach alpha value of 0.83 confirmed the reliability and internal consistency of the questionnaire. A structured questionnaire was developed through extensive review of literature and by using standard treatment guidelines for the management of hepatitis B and C. The National hepatitis Control of Pakistan guidelines were chosen as reference for the development of questionnaire. The questionnaire was comprised of 4 sections. The first section included information regarding prescriber's demographic characteristics: gender, city, sector (public/private) and type of healthcare facility, profession and years of experience. In the second section, perceptions of prescribers regarding current treatment practices for hepatitis B and C in the country were explored. The perceptions of prescribers regarding contributing factors towards lack of adherence to STGs including patient-related factors, availability and accessibility of the guidelines for reference, prescriber's experience/ personal preference and lack of guideline enforcement were explored. Sections 2 and 3 of the questionnaire included a set of statements in which respondents were asked to indicate their level of agreement using a 5-point Likert scale where $1=$ strongly disagree, $2=$ disagree; $3=$ neutral, $4=$ agree and $5=$ strongly agree was used. In the last section, the knowledge of prescribers regarding standard treatment regimens for different currently available anti-HBV and $\mathrm{HCV}$ agents and inclusion and exclusion criteria for management of hepatitis B and C was assessed. Responses were assigned as $1=$ yes/correct and $2=$ no/ incorrect. The composite score range was $12-24$ and a lower score indicated better knowledge.

\section{Data collection}

Two teams, one in each city, with 10 data collectors in each team, were trained by the group of experts including the principal investigator. The questionnaire was hand-delivered to prescribers by the data collectors. Informed and verbal consent for participation was taken from the respondents. Respondents were assured about the confidentiality of information verbally and were shown an undertaking signed by the principal investigator. The questionnaire was self-completed by the prescribers and was collected from them on the same day.

\section{Data analysis}

Data was collected by the principal investigator. The questionnaire was hand-delivered to prescribers by the data collectors. Informed and verbal consent for participation was taken from the respondents. Respondents were assured about the confidentiality of information verbally and were shown an undertaking signed by the principal investigator. The questionnaire was self completed by the prescribers and was collected from them on the same day. After data collection, data was cleaned, coded and entered in SPSS version. Skewness tests were performed and histograms with normal curves were used to check the normal distribution of data. Descriptive statistics of frequency and percentage was calculated. Kruskal-Wallis and MannWhitney tests $(\mathrm{p} \leq 0.05)$ were performed to find out differences among variables.

\section{Results}

\section{Background characteristics}

Out of 400 prescribers, $48 \%(n=192)$ were male while $52 \%(n=208)$ were female. Sixty one percent $(n=244)$ of the prescribers were working in public sector and thirty nine percent $(\mathrm{n}=156)$ prescribers were working in private healthcare facilities. Of the total respondents, $41 \%(n=164)$ were house officers, $40 \%(n=160)$ were medical officers, $10.25 \%(\mathrm{n}=41)$ were general practitioners and $8.8 \%(\mathrm{n}=35)$ were specialists. A detailed description is given(Table 1).

\section{Prescribers' opinions regarding management of hepa- titis $B$ and $C$ in Pakistan}

The results highlighted that $43.8 \%(n=175)$ prescribers were satisfied with the current available medicines for management of hepatitis B and C in Pakistan. Forty five percent $(n=182)$ respondents agreed on the availability of guidelines .On the other hand, 
$39.8 \%(n=159)$ prescribers working in different healthcare facilities reported that prescribing medicines for hepatitis $\mathrm{B}$ and $\mathrm{C}$ according to guidelines is not cost effective. Eighty percent prescribers $(n=320)$ had

Table I Background characteristics of the sample of prescribers $(n=400)$ the opinion that lack of availability and implementation of STGs in hospitals is an important factor which affects overall cost of hepatitis $\mathrm{B}$ and $\mathrm{C}$ treatment. A detailed description is given(Table 2).

\begin{tabular}{ll}
\hline Variable & $\mathbf{n}(\%)$ \\
\hline Gender & \\
Male & $192(48.0)$ \\
Female & $208(52.0)$ \\
Sector & \\
Public & $244(61.0)$ \\
Private & $156(39.0)$ \\
City & \\
Islamabad & $122(30.5)$ \\
Rawalpindi & $278(69.5)$ \\
Profession & \\
House officer & $164(41.0)$ \\
Medical officer & $160(40.0)$ \\
Specialist & $35(8.8)$ \\
General practitioner & $41(10.2)$ \\
Experience(years) in treating hepatitis B and C & \\
$<$ I & \\
I-5 & $232(58.0)$ \\
\hline I0 & $99(24.7)$ \\
\hline
\end{tabular}

Table 2 Prescribers' opinions regarding management of hepatitis B and C in Pakistan

\begin{tabular}{|c|c|c|c|}
\hline \multirow[t]{2}{*}{ Item } & \multicolumn{3}{|c|}{ Prescribers' opinions(n=400) } \\
\hline & $\begin{array}{l}\text { Strongly agree }+ \text { agree } \\
\mathrm{n}(\%)\end{array}$ & Neutral n(\%) & $\begin{array}{l}\text { Strongly disagree + disagree } \\
\mathrm{n}(\%)\end{array}$ \\
\hline $\begin{array}{l}\text { Do you think hepatitis } B \text { and } C \text { is well controlled } \\
\text { with current available medicines in healthcare } \\
\text { system of Pakistan? }\end{array}$ & $175(43.8)$ & $94(23.5)$ & $131(32.8)$ \\
\hline $\begin{array}{l}\text { Guidelines on treatment of hepatitis B and C are } \\
\text { available in healthcare facilities of Pakistan. }\end{array}$ & $182(45.5)$ & $77(19.3)$ & $14 \mid(35)$ \\
\hline $\begin{array}{l}\text { In your opinion, do you think screening criteria for } \\
\text { hepatitis } B \text { and } C \text { is well established in Pakistan? }\end{array}$ & $148(37)$ & $80(20)$ & 172(43) \\
\hline $\begin{array}{l}\text { In your opinion, prescribing medicines for hepatitis } \\
B \text { and } C \text { according to guidelines is cost effective. }\end{array}$ & 176(44) & $65(16.3)$ & 159(39.8) \\
\hline
\end{tabular}


Table Continued..

\begin{tabular}{|c|c|c|c|}
\hline \multirow[t]{2}{*}{ Item } & \multicolumn{3}{|c|}{ Prescribers' opinions $(n=400)$} \\
\hline & $\begin{array}{l}\text { Strongly agree + agree } \\
\mathrm{n}(\%)\end{array}$ & Neutral n(\%) & $\begin{array}{l}\text { Strongly disagree + disagree } \\
n(\%)\end{array}$ \\
\hline $\begin{array}{l}\text { Do you think treatment for hepatitis B should be } \\
\text { stopped during Ist trimester of pregnancy? }\end{array}$ & $214(53.5)$ & II2(28) & $74(18.5)$ \\
\hline $\begin{array}{l}\text { In your opinion, Complete blood picture and } \\
\text { ALT every month should be part of follow up for } \\
\text { hepatitis patient. }\end{array}$ & $326(81.5)$ & $30(7.5)$ & $44(I I)$ \\
\hline $\begin{array}{l}\text { In your opinion, } \mathrm{Hb}<8 \text { and TLC/Platelets around } \\
2500-40,000 \text { is marker for reduction of anti-HCV } \\
\text { therapy? }\end{array}$ & $250(62.5)$ & $95(23.8)$ & $55(\mid 3.8)$ \\
\hline $\begin{array}{l}\text { Do you think pregnant and lactating women; low } \\
\mathrm{Hb} \text { cases and patients with uncontrolled diabetes } \\
\text { require observation but not treatment? }\end{array}$ & $142(35.5)$ & $119(29.7)$ & $139(34.7)$ \\
\hline $\begin{array}{l}\text { In your view, viral suppression should be ultimate } \\
\text { goal of therapy for hepatitis? }\end{array}$ & $276(69)$ & $52(13)$ & $72(18)$ \\
\hline $\begin{array}{l}\text { The lack of availability and implementation of STGs } \\
\text { in hospitals is an important factor which affects } \\
\text { overall cost of hepatitis B and C treatment. }\end{array}$ & $320(80)$ & $52(13)$ & $28(7)$ \\
\hline $\begin{array}{l}\text { The poor regulation, insufficient on-job training, } \\
\text { influence of peers, patient demand and high } \\
\text { treatment cost is among the contributing factors } \\
\text { for prevalence of hepatitis } B \text { and } C \text { in Pakistan. }\end{array}$ & $332(83)$ & $34(8.5)$ & $34(8.5)$ \\
\hline $\begin{array}{l}\text { Do you think there is a need for more educational } \\
\text { programs to increase knowledge and awareness } \\
\text { on the available guidelines? }\end{array}$ & $383(95.7)$ & $7(1.7)$ & $10(2.5)$ \\
\hline
\end{tabular}

Prescribers' knowledge regarding standard inclusion and exclusion criteria used for treatment of hepatitis $B$ and $C$

Out of total respondents, $21.7 \%(\mathrm{n}=87)$ prescribers considered liver cirrhosis as an inclusion criteria for hepatitis B treatment whereas $24.2 \%(n=97)$ prescribers considered liver cirrhosis as an exclusion criteria for hepatitis B management. The results of study reported that HBV detected through PCR was reported as inclusion criteria by $70.5 \%(n=282)$ prescribers while $23.7 \%(n=95)$ prescribers considered decompensating serum albumin as a marker to initiate anti HBV treatment in healthcare facilities of Pakistan. Results of the present study also highlighted that $27.2 \%(\mathrm{n}=111)$ respondents were of the opinion that renal failure is considered as an inclusion criteria in treatment of hepatitis $\mathrm{C}$ whereas $43 \%(\mathrm{n}=172)$ considered heart disease as an important marker to be considered while treating hepatitis patient. Twenty eight percent $(\mathrm{n}=112)$ prescribers considered pregnancy/lactation as an exclusion criteria for management of hepatitis C. A detailed description is given (Table 3).

Prescribers' knowledge regarding standard baseline tests and treatment for hepatitis B and C

The results of the study reported that $91.5 \%(\mathrm{n}=366)$ prescribers were of the opinion that blood complete picture should be performed as baseline test after induction of anti-HCV treatment in healthcare facilities. ALT was declared as an important marker to monitor management of hepatitis $\mathrm{C}$ by $93.7 \%(\mathrm{n}=375)$ respondents. Liver biopsy was considered as a baseline test in addition to other tests by thirty two percent $(n=129)$ respondents. The study findings also showed that $41.7 \%(\mathrm{n}=167)$ prescribers in both cities identified Lamivudine $100 \mathrm{mg} /$ day oral as a most effective drug in treatment of hepatitis B and $\mathrm{C}$ whereas seventy five percent $(\mathrm{n}=300)$ respondents in public and private healthcare sector of twin cities agreed that ribazole $400 \mathrm{mg}$ PO BID is a safe dose for anti HBV and HCV treatment. Exemption of relapsed cases or dialysis patients from treatment was reported by fifty two $(n=209)$ prescribers in healthcare facilities of both cities. A detailed description is given (Table 4). The composite scores for knowledge were taken into account when assessing the knowledge of prescribers for the whole therapeutic regimen. Significant differences $(p \leq 0.05)$ were found among the knowledge scores of prescribers with different designations. Prescribers working as house officers had significantly better knowledge. While no significant differences $(p \leq 0.05)$ were found between the genders, sector, different level of experience and city (Table 5). 
Table 3 Prescribers' knowledge regarding standard inclusion and exclusion criteria used for treatment of hepatitis B and C

\begin{tabular}{|c|c|c|c|c|c|}
\hline \multicolumn{6}{|l|}{ Hepatitis B } \\
\hline Inclusion criteria & $\begin{array}{l}\text { Correct } \\
\mathbf{n}(\%)\end{array}$ & $\begin{array}{l}\text { Incorrect } \\
\text { n(\%) }\end{array}$ & Exclusion criteria & $\begin{array}{l}\text { Correct } \\
\mathrm{n}(\%)\end{array}$ & $\begin{array}{l}\text { Incorrect } \\
\text { n(\%) }\end{array}$ \\
\hline Age 9-50yr & $275(68.7)$ & $125(31.2)$ & Age 9-50yr & $50(12.5)$ & $350(87.5)$ \\
\hline Age $<9 y r$ and $>55 y r$ & $120(30)$ & $280(70)$ & Age $<9 y r$ and $>55 y r$ & $130(32.5)$ & $270(67.5)$ \\
\hline Liver cirrhosis & $87(21.7)$ & $313(78.2)$ & Liver cirrhosis & $97(24.2)$ & $303(75.7)$ \\
\hline $\begin{array}{l}\text { HBV DNA detected through } \\
\text { PCR }\end{array}$ & $282(70.5)$ & II8(29.5) & $\begin{array}{l}\text { HBV DNA detected through } \\
\text { PCR }\end{array}$ & $31(7.7)$ & $369(92.2)$ \\
\hline $\begin{array}{l}\text { Decompensating serum } \\
\text { albumin }\end{array}$ & $95(23.7)$ & $305(76.2)$ & $\begin{array}{l}\text { Decompensating serum } \\
\text { albumin }\end{array}$ & $52(13)$ & $348(87)$ \\
\hline \multicolumn{6}{|l|}{ Hepatitis C } \\
\hline Age $>60 \mathrm{yr}$ & $|3|(32.7)$ & $269(67.2)$ & Age $>60 y r$ & $95(23.7)$ & $305(76.2)$ \\
\hline Age $6-60 \mathrm{yr}$ & $240(60)$ & $160(40)$ & Age 6-60yr & $72(18)$ & $328(82)$ \\
\hline Renal failure & III(27.7) & $289(72.2)$ & Renal failure & $8 I(20.2)$ & $319(79.7)$ \\
\hline HCV RNA(PCR) detected & $318(79.5)$ & $82(20.5)$ & HCV RNA(PCR) detected & $4 I(10.2)$ & $359(89.7)$ \\
\hline Heart disease & $172(43)$ & $228(57)$ & Heart disease & $97(24.2)$ & $303(75.7)$ \\
\hline Pregnancy/lactation & $15 \mathrm{I}(37.7)$ & $249(62.2)$ & Pregnancy/lactation & $112(28)$ & $288(72)$ \\
\hline Neutropenia & $133(33.2)$ & $267(66.7)$ & Neutropenia & $108(27)$ & 292(73) \\
\hline Thrombocytopenia & $124(3 \mid)$ & $276(69)$ & Thrombocytopenia & $104(26)$ & $296(74)$ \\
\hline
\end{tabular}

Table 4 Prescribers' knowledge regarding standard baseline tests and treatment for hepatitis B and C

\begin{tabular}{|c|c|c|}
\hline Item & Correct n(\%) & Incorrect n(\%) \\
\hline \multicolumn{3}{|l|}{ Baseline tests } \\
\hline Blood CP & $366(91.5)$ & $34(8.5)$ \\
\hline ALT & $375(93.7)$ & $25(6.2)$ \\
\hline Serum albumin & $316(79)$ & $84(21)$ \\
\hline Ultrasound abdomen & 284(7I) & $116(29)$ \\
\hline Blood sugar & $166(4 \mid .5)$ & $234(58.5)$ \\
\hline Serum creatinine & $25 I(62.7)$ & $149(37.2)$ \\
\hline Thyroid function & $173(43.2)$ & $227(56.7)$ \\
\hline Liver biopsy & $129(32.2)$ & $27 I(67.7)$ \\
\hline \multicolumn{3}{|l|}{ Standard drug regimen } \\
\hline Lamivudine $100 \mathrm{mg} /$ day oral & $167(4 \mid .7)$ & $233(58.2)$ \\
\hline Peg INF 3MIU3 times/week for 6 months & $300(75)$ & $100(25)$ \\
\hline Ribazole $400 \mathrm{mg}$ oral BID or TID & $264(66)$ & 136(34) \\
\hline Most reported side effect of ribazole is anemia & 195(48.7) & $205(51.2)$ \\
\hline Reduce or stop INF dose if $\mathrm{Hb}$ falls below 6 & $25 I(62.7)$ & $149(37.2)$ \\
\hline Relapsed cases and dialysis patients are often exempted from treatment & $209(52.2)$ & $191(47.7)$ \\
\hline
\end{tabular}


Table 5 Comparison of prescribers' knowledge scores about standard treatment of Hepatitis B \& C by demographic characteristics

\begin{tabular}{|c|c|c|c|c|}
\hline \multirow[t]{2}{*}{ Variable } & \multicolumn{4}{|c|}{ Knowledge score } \\
\hline & $\mathbf{n}$ & $\begin{array}{l}\text { Mean } \\
\text { score }\end{array}$ & Test statistics & p-value \\
\hline \multicolumn{5}{|l|}{ Gender } \\
\hline Male & 192 & 192.3 & \multirow{2}{*}{$18411.5^{b}$} & \multirow{2}{*}{0.172} \\
\hline Female & 208 & 207.9 & & \\
\hline \multicolumn{5}{|l|}{ Sector } \\
\hline Public & 244 & 193.7 & \multirow{2}{*}{$17391.5^{b}$} & \multirow{2}{*}{0.141} \\
\hline Private & 156 & 211 & & \\
\hline \multicolumn{5}{|l|}{ City } \\
\hline Islamabad & 122 & 185.4 & \multirow{2}{*}{$15124.0^{\circ}$} & \multirow{2}{*}{0.081} \\
\hline Rawalpindi & 278 & 207.1 & & \\
\hline \multicolumn{5}{|l|}{ Designations } \\
\hline Specialist & 35 & 206.7 & \multirow{5}{*}{$8.582^{\mathrm{a}}$} & \multirow{5}{*}{0.035} \\
\hline $\begin{array}{l}\text { Medical } \\
\text { Officer House }\end{array}$ & 160 & 210.1 & & \\
\hline & & & & \\
\hline Officer & 164 & 182.0 & & \\
\hline $\begin{array}{l}\text { General } \\
\text { Practitioner }\end{array}$ & 41 & 231.5 & & \\
\hline \multicolumn{5}{|l|}{ Experience } \\
\hline$<$ I year & 232 & 207.5 & \multirow{4}{*}{$3.60 \mathrm{I}^{\mathrm{a}}$} & \multirow{4}{*}{0.308} \\
\hline I-5years & 37 & 197.5 & & \\
\hline 6-10years & 32 & 170.9 & & \\
\hline > I0years & 99 & 192.4 & & \\
\hline
\end{tabular}

${ }^{a}$ Kruskal-wallis and bMann-whitney tests $(p \leq 0.05)$

\section{Discussion}

The morbidity and mortality associated with hepatitis $\mathrm{B}$ virus(HBV) and hepatitis $\mathrm{C}$ virus(HCV) infections is rising rapidly and indicates a major public health burden in Pakistan. The timely detection of chronically infected persons, with follow-up and case management, is crucial. The results of the current study highlighted that nearly half of the prescribers were satisfied with the currently available medicines for control of hepatitis in the country. However unnecessary injection use, blood transfusions, poor economic status, less awareness and high cost of therapy were highlighted as the main factors contributing of high prevalence of Hepatitis B and C infection in the country. The standard treatment guidelines are main tool in achieving rational prescribing practices. Majority of the physicians agreed that guidelines are available in various healthcare facilities. Similar results were reported in study where availability of guidelines was ensured to address management issues in hepatitis. ${ }^{4}$ The results of the study highlighted that nearly half of the respondents were dissatisfied with the current screening criteria of the disease. The results of the present study showed that majority of the respondents agreed that prescribing from the STGs was cost effective and there is a need for more educational programs to increase knowledge and awareness about the available treatment guidelines for Hepatitis B and
C. Similar results were reported in a study conducted in Europe where prescribers agreed that effective interventions should be adopted for the dissemination and implementation of the existing guidelines for control of chronic hepatitis. ${ }^{5}$ The results of the study highlighted that majority of the prescribers were of the view that lack of availability and implementation STGs in hospitals affects overall cost of hepatitis B and $\mathrm{C}$ treatment. The results of the current study highlighted that most of the respondents were of the view that poor regulation, insufficient on-job training, influence of peers, patient demand and high treatment cost were the main contributing factors for prevalence of hepatitis B and $\mathrm{C}$ in Pakistan. Similar findings were reported from several other studies conducted in other developing countries. ${ }^{6,7}$ The results of the current study highlighted that most of the prescribers were of the view that treatment for hepatitis B should be stopped during 1st trimester of pregnancy. The results of the study showed that majority of the prescribers were aware of the lab criteria required to check response of therapy. Majority agreed that complete blood picture and ALT every month should be part of follow up for hepatitis patient. Majority of the respondents agreed that $\mathrm{Hb}<8$ and TLC/Platelets around 250040,000 is marker for reduction of anti-HCV therapy. Similar findings were reported in a study conducted in Australia where majority of the practitioners were well aware of the screening tests required for chronic hepatitis. ${ }^{8}$ The results of the study highlighted that half of the respondents agreed that pregnant and lactating women, low $\mathrm{Hb}$ cases and patients with uncontrolled diabetes require observation but not treatment. The results of the current study highlighted that majority of the prescribers agreed that viral suppression should be ultimate goal of therapy for hepatitis. Similar results were reported in a study conducted in Turkey. ${ }^{9}$ The results of the current study highlighted that majority of the prescribers had poor knowledge regarding inclusion and exclusion criteria of hepatitis $\mathrm{B}$ and $\mathrm{C}$. This might be due to lack of implementation of standard treatment guidelines in healthcare facilities leading to poor knowledge of prescribers. Similar findings were reported in various studies where knowledge of practitioners regarding screening for treatment was low. ${ }^{10}$ The results of the study reported that majority of the prescribers working in either public or private healthcare facilities were aware of the correct baseline tests for HCV recommended after induction of management. Majority of the them also considered ALT as an important marker to monitor management of hepatitis C. Similar findings were reported in studies conducted in China. ${ }^{11,12}$ Antiviral treatment is the only way to reduce morbidity and mortality from chronic HBV infection. Conventional interferon alfa and Lamivudine have been the primary treatments to date. ${ }^{1}$ The results of the study highlighted that majority of the prescribers were aware of the effective dosage regimen of individual drugs used for hepatitis. Majority of the prescribers considered ribazole and peg-interferon as an effective drug for treatment of hepatitis. Similar results were reported in a study conducted in Netherlands where most of the patients were treated according to the available guidelines. ${ }^{13}$ However, significant differences were found among the knowledge scores of different specialists. House officers had better knowledge whereas general practitioners had low levels of knowledge as compared to other groups of practitioners. This might be due to the fact that house officers practice in tertiary healthcare facilities under the supervision of specialists as compared to general practitioners who have less access to guidelines and are less aware of the rational prescribing practices. Similar results were reported in a study conducted in Pakistan where house officers had better levels of knowledge regarding treatment of hepatitis B and C..$^{14}$ 


\section{Conclusion}

The results of the present study concluded that the knowledge of prescribers working in public and private healthcare facilities regarding hepatitis B \& C guidelines was not adequate but they had positive perceptions towards adherence to these guidelines linked to their availability in their healthcare facilities. This highlights the need for revamping the mechanism for dissemination of the guidelines by the hepatitis control program of Pakistan. Appropriate training programs for prescribers regarding inclusion \& exclusion criteria for diagnosis and choice of antiviral therapy must be designed to improve provider compliance with the standard guidelines which can help to control hepatitis in Pakistan.

\section{Acknowledgements}

None.

\section{Conflict of interest}

Author declares that there is no conflict of interest.

\section{References}

1. Lavanchy D. Hepatitis B virus epidemiology, disease burden, treatment, and current and emerging prevention and control measures. $J$ Viral Hepat. 2004;11(2):97-107.

2. Shepard CW, Finelli L, Alter MJ. Global epidemiology of hepatitis C virus infection. Lancet Infect Dis. 2005;5(9):558-567.

3. Umar M, Khaar HT, Akhter TS, et al. Diagnosis, management and prevention of hepatitis C. J Ayub Med Coll Abbottabad. 2016;28(Suppl 1)(4):S839-S882.

4. Muhammad U, Bushra H, Ahmad M, et al. Hepatitis C in Pakistan: a review of available data. Hepat Mon. 2010;10(3):205-214.
5. Bechini A, Falla A, Ahmad A, et al. Identification of hepatitis B and C screening and patient management guidelines and availability of training for chronic viral hepatitis among health professionals in six European countries: results of a semi-quantitative survey. BMC Infectious Dis. 2015; $15: 353$

6. Xu WM, Cui YT, Wang L, et al. Lamivudine in late pregnancy to prevent perinatal transmission of hepatitis $\mathrm{B}$ virus infection: a multicentre randomized, double-blind, placebo-controlled study. J Viral Hepat. 2009;16(2):94-103.

7. Lu J, Zhou Y, Lin X, et al. General epidemiological parameters of viral hepatitis A, B, C, and $\mathrm{E}$ in six regions of China: a cross-sectional study in 2007. PLoS One. 2009;4(12):e8467.

8. Guirgis M, Yan K, Bu YM, et al. General practitioners' knowledge and management of viral hepatitis in the migrant population. Intern Med J. 2012;42(5):497-504.

9. Peksen Y, Canbaz S, Hakan L, et al. Primary care physicians' approach to diagnosis and treatment of hepatitis $\mathrm{B}$ and hepatitis $\mathrm{C}$ patients. BMC gastroenterology. 2004;4:3.

10. Zickmund SL, Brown KE, Bielefeldt K. A systematic review of provider knowledge of hepatitis C: is it enough for a complex disease? Dig Dis Sci. 2007;52(10):2550-2556.

11. Lai CL, Gane E, Liaw YF, et al. Telbivudine versus lamivudine in patients with chronic hepatitis B. N Engl J Med. 2007;357(25):2576-2588.

12. Chao J, Chang ET, So SK. Hepatitis B and liver cancer knowledge and practices among healthcare and public health professionals in China: a cross-sectional study. BMC Public Health. 2010;10:98.

13. Slavenburg S, Lamers MH, Roomer R, et al. Current clinical care compared with new Dutch guidelines for hepatitis C treatment. Neth $J$ Med. 2009;67(5):177-181.

14. Babar FR, Yar A, Rana MJA. Knowledge, Attitude and Practice regarding Hepatitis B and C among house officers-A Study. Pakistan Oral \& Dental Journal. 2016;36(2):289-292. 